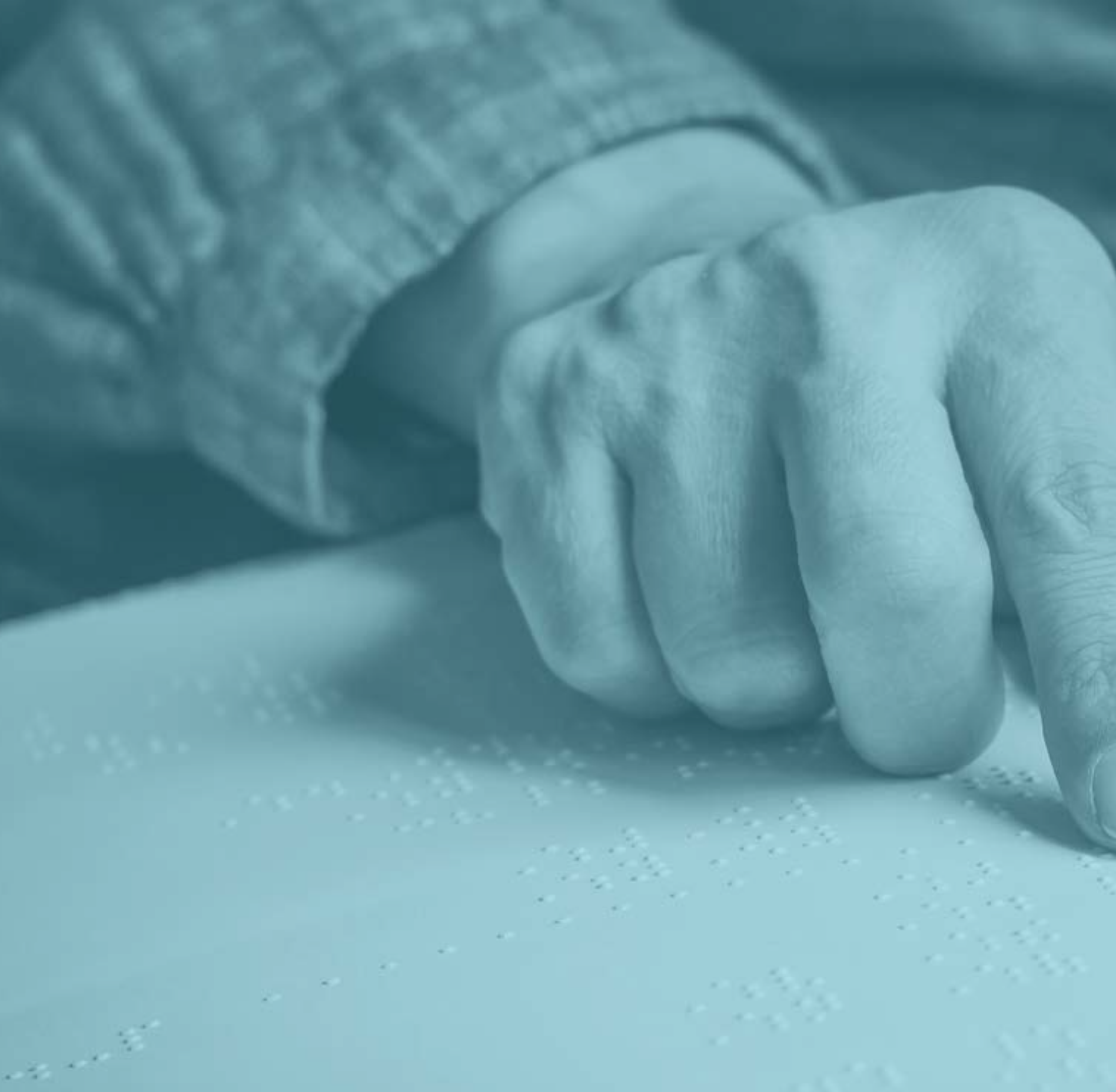




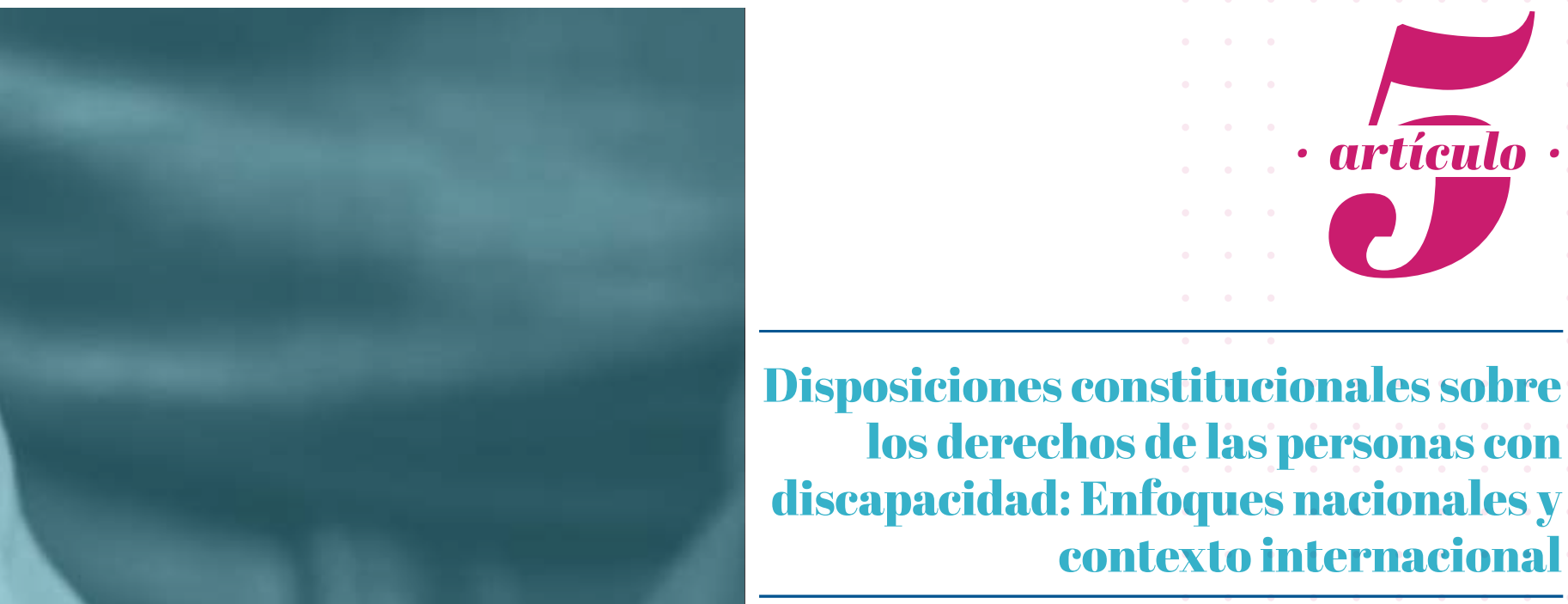

Gonzalo Moreno, ${ }^{164}$ Michael Ashley Stein ${ }^{165}$ y Jody Heymann ${ }^{166}$

DOI: $10.53110 / M E J 07213$

A. Introducción: Según la Organización Mundial de la Salud (OMS), más de mil millones de personas - cerca del 15\% de la población mundial - tiene algún tipo de discapacidad. ${ }^{167} \mathrm{~A}$ este grupo se le ha llamado la minoría más grande del mundo, ${ }^{168}$ sin embargo siguen viviendo discriminación y sesgo a nivel mundial. En las últimas dos décadas, el Movimiento por los Derechos de las Personas con Discapacidad ha conseguido un importante progreso en fomentar el reconocimiento de los derechos humanos y libertades fundamentales de dicho colectivo, culminando en 2006 con la Convención Internacional sobre los Derechos de las Personas con Discapacidad (CDPD). Como declaraciones de valores nacionales, modelos para futuras leyes y factores cruciales para decisiones judiciales y reformas legales, las constituciones se han convertido en herramientas de gran importancia tanto para derribar las barreras existentes como para implementar las obligaciones integrales y holísticas creadas por el CDPD.

164 Analista político Senior del Centro de Análisis de Políticas de WORLD, Universidad de California en Los Ángeles.

165 Director ejecutivo del Proyecto sobre Discapacidad de la Facultad de Derecho de Harvard; profesor visitante de la Facultad de Derecho de Harvard; profesor extraordinario del Centro de Derechos Humanos de la Facultad de Derecho de la Universidad de Pretoria.

166 Directora fundadora del Centro de Análisis de Políticas de WORLD; profesora distinguida de la Escuela de Salud Pública Fielding, la Escuela de Asuntos Públicos Luskin y la Escuela de Medicina Geffen de la Universidad de California en Los Ángeles.

167 World Health Organization, 2020.

168 United Nations Enable, sin fecha. 
Este capítulo se basa en datos comparativos globales de disposiciones constitucionales, junto con precedentes históricos en el ámbito jurídico basados en esas disposiciones, para destacar la medida en que las constituciones del mundo protegen los derechos fundamentales de las personas con discapacidad. La información que presentamos es parte de una base de datos cuantitativa de derechos constitucionales de los 193 estados miembros de la ONU, vigentes desde el 2017 y creada por el WORLD Policy Analysis Center (WORLD), en la Universidad de California, Los Ángeles. ${ }^{169}$

Nuestros datos muestran que, en las últimas décadas, las constituciones se han vuelto paulatinamente (y específicamente) protectoras de los derechos y libertades de las personas con discapacidad. Aún cuando estas protecciones son relativamente infrecuentes a través de todos los países, eso no debe opacar los recientes avances desde la adopción de la CDPD. Nuestros datos también demuestran que promulgar nuevas constituciones -en oposición a reformarlas - ofrece la mejor vía tanto para incorporar las nuevas provisiones de la CDPD, como para, generalmente, expandir las protecciones constitucionales de las personas con discapacidad. Chile, uno de los signatarios originales de la CDPD, tiene una oportunidad única de incorporar fuertes protecciones de los derechos de las personas con discapacidad en su nueva constitución.

B. Alrededor del mundo, las personas con discapacidad enfrentan obstáculos importantes en la educación, empleo y atención sanitaria. En los países

El contexto internacional de los derechos de las personas con discapacidad de ingresos medios y bajos, las cifras de matrículas escolares de niños con discapacidad son normalmente 30-50 puntos porcentuales más bajas que aquellas de niños sin discapacidad; ${ }^{170}$ y aquellos niños con discapacidad que llegan a matricularse en la educación, a menudo sufren discriminación o reciben una educación de baja calidad. ${ }^{171}$

\footnotetext{
169 Además de los datos sobre los derechos constitucionales de las personas con discapacidad, esta base de datos de libre acceso incluye información global sobre enfoques a la igualdad y la no discriminación entre razas/etnias, sexo/género, situación migratoria, identidad de género, estatus socioeconómico, como también disposiciones constitucionales sobre la educación, salud, familia, religión y una variedad de derechos políticos. Para aprender más sobre la metodología de WORLD, consulte la sección correspondiente en la web de la organización (WORLD Constitutional Rights Database - Methods) y en el anexo ("Methods" Advancing Equality), escrito por Heymann, Sprague y Raub. 2020. Puede acceder a los datos de WORLD en www.worldpolicycenter. org. Para un mayor análisis sobre el papel de los tribunales en la aprobación de la Convención Internacional de las Personas con Discapacidad, recomendamos consultar Lawson and Waddington, 2018.
} 
También existen disparidades en la educación cuando las personas con discapacidad entran en el mercado laboral. En 27 países de la Organización para la Cooperación y el Desarrollo Económicos, la tasa agregada de empleo de personas con discapacidad en edad laboral a finales del 2000 era de un $44 \%$ comparado con un $75 \%$ de las personas en edad laboral sin discapacidad. ${ }^{172}$ Incluso estando empleadas, las personas con discapacidad tienen más probabilidades en cargos de tiempo parcial ${ }^{173}$ y de ganar sueldos más bajos, ${ }^{174}$ y también de enfrentarse a barreras más grandes de desarrollo profesional. ${ }^{175}$

Las personas con discapacidad también encuentran limitaciones en el acceso a la atención sanitaria de calidad. ${ }^{176}$ En un estudio hecho por la OMS, las personas con discapacidad reportaron mayores necesidades de atención hospitalaria y ambulatoria, a la vez que mayores probabilidades de no recibir esa atención que las personas sin discapacidad. ${ }^{177}$ El mismo estudio sintetiza las desigualdades en el acceso a la asistencia médica y sanitaria en áreas tan diversas como la detección de cáncer, la salud sexual y reproductiva y el cuidado dental. ${ }^{178}$

Las personas con discapacidad también son más propensas a experimentar violaciones o restricciones de sus derechos civiles y políticos, incluido el derecho a votar, casarse o tener hijos, y generalmente de ejercer su capacidad legal. ${ }^{179}$ Entornos jurídicos que les niegan a las personas con discapacidad su derecho a participar en la vida política -una de las vías fundamentales a través de la que los grupos marginalizados buscan la igualdad de manera más efectiva-, ${ }^{180}$ constriñen severamente sus posibilidades de defender por sí mismos el reconocimiento de sus derechos. Esto incluye barreras sociales y ambientales, como casetas de votación inaccesibles o prácticas regresivas

170 Filmer, 2008, p. 141.

171 Harpur and Stein, 2019, p. 139; Heymann y McNeill, 2013; United Nations

Educational, Scientific and Cultural Organization, 2014.

172 Organisation for Economic Co-operation and Development, 2010, p. 21.

173 Jones, 2007, p. 695; Ibíd., Organisation for Economic Co-operation and Development, 2010, p. 52; Schur, 2002, p. 601.

174 Maldonado, 2006; Mitra y Sambamoorthi, 2009, p. 1393; Op. Cit., Organización para la Cooperación y el Desarrollo Económico, 2010, pp. 53-54.

175 Wilson-Kovacs et al., 2008, p. 705.

176 Drew et al., 2011, pp. 1664-1675; Evans et al., 2012, p. 1098; Mannan et al., 2012, p. 67; Stein et al., 2009, p. 1796.

177 World Health Organization, 2011, p. 60.

178 Ibíd., pp. 61-62.

179 See e.g. Drew et al., 2011; Redley et. al., 2012, p. 1026.

180 Fiala-Butora, Stein y Lord, 2014, p. 83. 
empleadas por las comisiones electorales. ${ }^{181}$ Las personas con discapacidad también enfrentan un riesgo especialmente alto de confinamiento involuntario. Por ejemplo, los niños con discapacidad en el Centro y Este de Europa son 17 veces más propensos a ser institucionalizados que aquellos sin discapacidad. ${ }^{182}$

El reconocimiento global de los derechos de las personas con discapacidad ha avanzado considerablemente en el último medio siglo. El creciente movimiento por los derechos de las personas con discapacidad, liderado por organizaciones de personas con discapacidad (OPD), ha llamado la atención sobre la insuficiencia de los términos generales usados en la Declaración Universal de los Derechos Humanos, en el Pacto Internacional de Derechos Económicos, Sociales y Culturales y en el Pacto Internacional de Derechos Civiles y Políticos, que falló en abordar las necesidades y obstáculos específicos que una persona con discapacidad enfrenta. ${ }^{183} \mathrm{El}$ movimiento culminó con la adopción de la CDPD, la que se convirtió en el primer tratado de derechos humanos de la ONU específicamente para personas con discapacidad.

La CDPD promueve un modelo de discapacidad orientado por los derechos humanos enfocado en el desmantelamiento de los obstáculos sociales, con el fin de conseguir "participación e inclusión plenas y efectivas en la sociedad" (Art. 3). Presenta un marco holístico para garantizar los derechos fundamentales de las personas con discapacidad, incluyendo el derecho a la igualdad y a la no discriminación (art. 5), accesibilidad (art. 9), ajustes razonables (art. 2), educación (art. 24) trabajo y empleo (art. 27), salud (art.25), libertad y seguridad de la persona (art.14), libertad de circulación (art. 18) y la participación en la vida política y pública (art.29). ${ }^{184}$

La CDPD está influenciando cada vez más la forma en que en las constituciones, y los tribunales que las interpretan, perciben los derechos y libertades de las personas con discapacidad. Por ejemplo, en la primera sentencia judicial de India que reconoció los ajustes razonables en el trabajo, ${ }^{185}$ el Tribunal Superior de Bombay tomó la definición de ajustes razonables de la CDPD para reforzar los derechos constitucionales a la igualdad, la igualdad en la oportunidades en el empleo, en la vida y en la libertad personal. ${ }^{186}$ Además, defensores de los derechos de las personas con discapacidad involucrados en procesos de reforma constitucional han utilizado la

\footnotetext{
181 A Ver Lord, Stein y Fiala-Butora, 2014, p. 115.

182 UNICEF, 2013.

183 Van Weele, 2012, p. 9.

184 Organización de Naciones Unidas, 2006.

185 Ranjit Kumar Rajak vs. State Bank of India, 2009.

186 Ver Constitución de India de 1949 (enmienda del 2016), arts. 14, 16 y 21.
} 
CDPD como un punto de referencia y un modelo para la incorporación de protecciones específicos de los derechos de las personas con discapacidad: Durante la redacción de la Constitución de Zambia del 2011, una coalición local de defensores de los derechos de las personas con discapacidad presionó por la inclusión del reconocimiento de la igualdad ante la ley de las personas con discapacidad, así como por la modificación de las disposiciones relacionadas con la capacidad legal y la toma de decisiones. ${ }^{187}$

A pesar de la creciente prominencia de protecciones constitucionales específicas para las personas con discapacidad, a nivel mundial estas protecciones siguen siendo relativamente infrecuentes en las áreas destacadas por las disposiciones de la CDPD:

\section{Igualdad y no discriminación}

Globalmente, el $27 \%$ de las constituciones prohíben la discriminación o garantizan la igualdad de derechos en relación con la discapacidad. Por ejemplo, la Constitución de Ecuador establece: "Todas las personas son iguales y gozarán de los mismos derechos, deberes y oportunidades. Nadie podrá ser discriminado por razones (...) discapacidad (...)" ${ }^{188}$ Esta es una proporción relativamente pequeña comparada con el número de constituciones que garantizan explícitamente la igualdad o la no discriminación de otros grupos protegidos: por ejemplo, el $85 \%$ de las constituciones establece garantías similares en base al sexo/genero, así como el $76 \%$ en base a la raza/grupo étnico. ${ }^{189}$

A pesar de estos comparativamente pequeños porcentajes, en general, las últimas décadas han visto un aumento constante en la proporción de constituciones que garantizan la igualdad de derechos para las personas con discapacidad. Mientras que el $11 \%$ de las constituciones actuales adoptadas antes de 1990 explícitamente garantizaban la igualdad de derechos o la no discriminación hacia las personas con discapacidad, el $71 \%$ de la constituciones adoptadas entre 2010-2017 sí lo hacen. A pesar de este desarrollo positivo, las constituciones de cinco países continúan garantizando la igualdad de derechos sólo en la medida en que las personas con discapacidad sean consideradas capaces de ejercerlos. Por ejemplo, la Constitución de Timor-Leste establece: Un ciudadano con discapacidad deberá gozar de

187 Lord y Stein, 2013, pp. 109-110.

188 Constitución de la Republica del Ecuador, 2008 (enmienda del 2015), art. 11(2).

189 Heymann, Sprague y Raub, 2020, pp. 22 y 49.
C.

Protección a los Derechos de las personas con discapacidad a nivel mundial 
los mismos derechos y estará sometido a los mismos deberes que el resto de ciudadanos, excepto por los derechos y deberes que él o ella es incapaz de ejercer o cumplir debido a su discapacidad". ${ }^{190}$ Disposiciones como la de Timor-Leste abren la puerta al trato discriminatorio al enfocarse en las limitaciones que se perciben en las personas con discapacidad, en vez de enfocarse en la igualdad y en los obstáculos ambientales cuya erradicación puede ayudar a maximizar la inclusión.

Las garantías constitucionales de igualdad específicas para las personas con discapacidad son herramientas invaluables para que los tribunales hagan cumplir los derechos de las personas con discapacidad. En 2014, la Corte Suprema de Justicia de México resolvió que un puesto de trabajo que especificaba que las personas con discapacidad no necesitaban postular era inconstitucional según los artículos 1 y 5 de la Constitución, ${ }^{191}$ que prohíben la discriminación por motivos de discapacidad y garantizan el derecho al trabajo, respectivamente. ${ }^{192}$ Las garantías constitucionales también pueden servir como un trampolín para la reforma legal: cuando Ecuador introdujo una ley integral de discapacidad en 2012, su preámbulo citó las disposiciones del artículo 11 (2) de la Constitución, citado anteriormente, como una de sus bases. ${ }^{193}$

No obstante, las garantías constitucionales generales de igualdad que carecen de un lenguaje específico para la discapacidad pueden en algunos contextos ser herramientas efectivas para promover la igualdad de derechos sobre la base de la discapacidad. ${ }^{194}$ Por ejemplo, citando la garantía general de igualdad en el artículo 14 de la Constitución, ${ }^{195}$ el Tribunal Superior de Delhi dictaminó que las personas sordas son aptas para tomar un examen de conducción. ${ }^{196}$ Sin embargo, los tribunales no siempre interpretan que las garantías generales de igualdad protegen específicamente a las personas con discapacidad. Por ejemplo, en 1927, la Corte Suprema de Estados Unidos desestimó un reclamo constitucional de igual protección y confirmó un estatuto que permitía la esterilización eugenésica involuntaria. ${ }^{197}$

\footnotetext{
190 Constitución de la República Democrática de Timor-Leste, 2002, sec. 21. Amparo Directo En Revisión, 2014.

Constitución de los Estados Unidos Mexicanos, 1917 (enmienda del 2017).

Ley Orgánica de Discapacidad, 2012.

Bryde y Stein, 2012, pp. 287-300.

Constitución de India

National Association of the Deaf vs. Union of India, 2011.

Buck vs. Bell, 1927.
} 


\section{Accesibilidad y ajustes razonables}

El artículo 9 de la CDPD insta a los Estados Partes a "asegurar el acceso de las personas con discapacidad, en igualdad de condiciones con las demás, al entorno físico, el transporte, la información y las comunicaciones, incluidos los sistemas y las tecnologías de la información y las comunicaciones, y a otros servicios e instalaciones abiertos al público o de uso público, tanto en zonas urbanas como rurales". A nivel mundial, sólo el $6 \%$ de las constituciones incluyen protecciones garantizadas o aspiracionales (es decir, protecciones expresadas en un lenguaje no autorizado) del derecho a la accesibilidad de los lugares públicos para las personas con discapacidad. Cuatro de las 193 constituciones incluyen disposiciones para garantizar la accesibilidad del transporte. Tres constituciones garantizan el derecho a utilizar el Braille como una forma alternativa de comunicación, al igual que cinco para el lenguaje de señas. Otro $4 \%$ de las constituciones se compromete a promover el uso de la lengua de señas.

Proporcionar ajustes razonables es esencial para contrarrestar las barreras al ejercicio de los derechos fundamentales, incluida la igualdad. El artículo 2 de la CDPD, por ejemplo, define los ajustes razonables como "las modificaciones y adaptaciones necesarias y adecuadas que no impongan una carga desproporcionada o indebida, cuando se requieran en un caso particular, para garantizar a las personas con discapacidad el goce o ejercicio, en igualdad de condiciones con las demás, de todos los derechos humanos y libertades fundamentales". Sólo dos de las 193 constituciones abordan directamente los ajustes razonables.

Aunque los tribunales pueden extender garantías constitucionales explícitas de igualdad a las personas con discapacidad para proporcionar el derecho a la accesibilidad y ajustes razonables -como la Corte Suprema de Canadá que, al citar la sección 15 de la Carta Canadiense de Derechos y Libertades, sostuvo que los hospitales deben proporcionar intérpretes para los sordos ${ }^{198}$-, la accesibilidad y los ajustes razonables siguen siendo, en la mayoría de los casos, la próxima frontera para la formulación de los derechos de las personas con discapacidad en los marcos constitucionales. ${ }^{199}$

198 Eldridge vs. British Columbia (Attorney General), 1997.

199 Esto es especialmente importante en un ambiente crecientemente interconectado, donde el acceso igualitario al mundo virtual es una preocupación real y al mismo tiempo una vía prometedora para la inclusión social. Ver Lazary Stein, 2017. 


\section{Derechos Sociales y Económicos}

\section{- Educación}

A nivel mundial, el 28\% de las constituciones garantizan los derechos educativos de los niños con discapacidad. El 19\% lo hace brindando esta garantía específicamente a los niños con discapacidad, mientras que otro $9 \%$ protege el derecho a la educación en general y al mismo tiempo garantiza el derecho a la igualdad o prohíbe la discriminación de las personas con discapacidad. El 14\% de las constituciones garantizan educación especializada o apoyo educativo general para niños con discapacidad, y el $2 \%$ exige específicamente que las escuelas sean accesibles para los niños con discapacidad.

Sin embargo, los mandatos constitucionales para la integración de los niños con discapacidad en los sistemas escolares generales siguen siendo poco frecuentes: sólo el 3\% de las constituciones garantizan explícitamente la integración educativa de los niños con discapacidad. Por ejemplo, la constitución de Bolivia establece: "El Estado promoverá y garantizará la educación permanente de niñas, niños y adolescentes con discapacidad, o con talentos extraordinarios en el aprendizaje, bajo la misma estructura, principios y valores del sistema educativo, y establecerá una organización y desarrollo curricular especial". ${ }^{200}$

Sin embargo, estas disposiciones pueden tener efectos profundos en el sistema educativo de un país. Por ejemplo, la Corte Suprema de Brasil desestimó una impugnación de un consorcio de escuelas privadas que afirmaba que una ley que obligaba a las escuelas privadas a brindar educación inclusiva era inconstitucional. El tribunal citó el artículo 208 de la Constitución, que obliga al Estado a implementar el derecho a la educación a través de "atención educacional especial a los portadores de deficiencias, preferentemente en el sistema ordinario de enseñanza", 201 y afirmó que todas las escuelas, ya sean públicas o privadas, tienen un deber constitucional de promover la educación inclusiva. ${ }^{202}$

\section{- Trabajo}

El $22 \%$ de las constituciones del mundo garantizan el derecho al trabajo de las personas con discapacidad; el $12 \%$ lo hace al hacer explícita esta garantía a los trabajadores con discapacidad, y un $10 \%$ adicional garantiza los derechos laborales para todos y prohíbe la discriminación en el empleo por

\footnotetext{
200 Constitución política del Estado Plurinacional de Bolivia, 2009, art. 85.

201 Constitución Política de la Republica Federativa del Brasil, 1988 (enmienda del 2017).

202 Acción directa de inconstitucionalidad, 2016.
} 
motivos de discapacidad al mismo tiempo. Por ejemplo, la constitución de Malawi establece: Toda persona tendrá derecho a un salario justo y a una remuneración igual por un trabajo de igual valor sin distinción ni discriminación de ningún tipo, en particular por motivos de género, discapacidad o raza. ${ }^{203}$ Un $10 \%$ adicional de las constituciones generalmente garantiza el derecho al trabajo o la no discriminación en el trabajo y, al mismo tiempo, garantiza la igualdad o prohíbe la discriminación de las personas con discapacidad. Sin embargo, dos constituciones de 193 -Dinamarca y Arabia Saudita-, continúan limitando el derecho al trabajo a los ciudadanos "capacitados", lo que podría abrir la puerta a la discriminación laboral contra adultos con discapacidades físicas. La sección 75(1) de la Ley Constitucional de Dinamarca establece que con "el fin de garantizar el bienestar general, todo ciudadano apto para trabajar debe tener la oportunidad de trabajar en condiciones susceptibles de asegurar su sustento".

\section{- Salud}

El $21 \%$ de las constituciones garantizan el derecho a la salud de las personas con discapacidad. El $13 \%$ lo hace proporcionando explícitamente esta garantía. Por ejemplo, la constitución de España establece: "Los poderes públicos realizarán una política de previsión, tratamiento, rehabilitación e integración de los disminuidos físicos, sensoriales y psíquicos a los que prestarán la atención especializada que requieran". ${ }^{204}$ Un $8 \%$ adicional de las constituciones garantiza el derecho a la salud de todos y, al mismo tiempo, garantiza la igualdad o prohíbe explícitamente la discriminación por motivos de discapacidad. Además, el $7 \%$ de las constituciones garantizan en general servicios médicos gratuitos, una disposición que, incluso si no se refiere explícitamente a las personas con discapacidad, puede sin embargo desempeñar un papel importante, dados los vínculos bien documentados entre discapacidad y pobreza. ${ }^{205}$

\section{Derechos Civiles y Políticos}

Las personas con discapacidad siguen encontrando restricciones explícitas y legalmente impuestas que han sido eliminadas en gran medida para otros grupos sociales marginados, a menudo en base a suposiciones sobre las personas con discapacidad en su totalidad, o sobre algún tipo de discapacidad en particular, sin tener en cuenta la diversidad entre las personas, las circunstancias y experiencias. 
El $25 \%$ de las constituciones del mundo protegen explícitamente el derecho a la libertad de las personas con discapacidad. De estos, el 10\% garantiza este derecho explícitamente y otro $15 \%$ garantiza el derecho a la libertad en general y al mismo tiempo protege la igualdad de derechos para las personas con discapacidad. Sin embargo, cinco de las constituciones que garantizan explícitamente el derecho a la libertad de las personas con discapacidad también incluyen restricciones potencialmente amplias a este derecho, como garantías de igualdad de derechos sólo en la medida en que se perciba que las personas con discapacidad pueden disfrutar de ellos, y nueve de estas constituciones protegen explícitamente el derecho a la libertad de las personas con discapacidad, pero hacen excepciones específicas para las condiciones de salud mental. Este tipo de disposición se ha utilizado históricamente para justificar el internamiento involuntario de personas con discapacidad en centros psiquiátricos o entornos de atención colectiva. En total, el $19 \%$ de todas las constituciones declaran explícitamente que se puede negar el derecho a la libertad a las personas con condiciones de salud mental. Cuatro constituciones también niegan la libertad de movimiento a las personas que no están "en su sano juicio".

- Voto y elegibilidad para cargos legislativos

La realización de los derechos fundamentales depende de que los países diseñen enfoques inclusivos. Los lugares de votación físicamente inaccesibles o los materiales y procedimientos que sólo funcionan para personas videntes son dos de los muchos ejemplos que con frecuencia restringen severamente los derechos de las personas con discapacidad en la práctica, incluso si tales limitaciones no están prescritas por la ley. Solo cinco constituciones contienen disposiciones diseñadas para facilitar el voto de las personas con discapacidad, y algunas están redactadas con más detalle que otras. Por ejemplo, mientras que la constitución de Uganda establece que el Parlamento promulgará leyes para facilitar que los ciudadanos con discapacidades se registren y voten, ${ }^{206}$ una disposición similar en la constitución de Malta menciona sólo a los votantes ciegos. ${ }^{207}$

Además, el $23 \%$ y el $32 \%$ de las constituciones en todo el mundo niegan potencialmente a las personas con condiciones de salud mental el derecho al voto y el derecho a ocupar cargos legislativos, respectivamente. Para las condiciones de salud física, las cifras son mucho más bajas, 3\% y $4 \%$ respectivamente. Por ejemplo, la Constitución de Uruguay establece

206 Constitución de la República de Uganda, 1995 (enmienda del 2017), 59(4).

207 Constitución de Malta, 1964 (enmienda del 2016), art. 56(10). 
que "La ciudadanía se suspende: $1^{\circ}$.Por ineptitud física o mental que impida obrar libre y reflexivamente", pero no especifica cómo las discapacidades físicas podrían impedir la acción reflexiva. ${ }^{208}$ Estas disposiciones no se interpretan necesariamente con cautela ni son intrascendentes. En Hungría, las restricciones generales al voto de las personas bajo tutela dieron lugar a la privación del derecho a voto de más de 71.000 personas $\mathrm{y}$, sin embargo, se consideró que solo de 8.000 a 12.000 de ellas tenían discapacidades "graves" o "profundas" que podrían afectar de manera plausible la capacidad de voto. ${ }^{209}$

Los datos que hemos presentado incluyen las constituciones de los $193 \mathrm{Es}$ tados miembros de la ONU, independientemente de si fueron enmendadas, cuándo y cómo. Por supuesto, las constituciones pueden modificarse con bastante frecuencia. Al momento de redactar este informe, la Constitución de Colombia tiene 29 años de vigencia y ha sido enmendada al menos una vez en 20 de esos años; en Brasil, esta cifra es al menos una vez en 27 de 32 años, y en México es 76 de 103 años. ${ }^{210}$ Las enmiendas pueden introducir -y a veces introducen- nuevos derechos para las personas con discapacidad. Por ejemplo, Guyana agregó la "discapacidad" como motivo protegido contra la discriminación en una enmienda de 2003 a su Constitución. ${ }^{211} \mathrm{Y}$ sin embargo, según los datos que hemos recopilado durante casi 15 años, la redacción de nuevas constituciones ha sido hasta ahora una vía más común para implementar y expandir los derechos de las personas con discapacidad.

Dado que las nuevas constituciones son mucho menos frecuentes que las enmiendas a las existentes, es relativamente raro que las circunstancias se alineen para que un país apruebe una nueva constitución que pueda tener en cuenta los compromisos y contextos internacionales recientemente adquiridos. En 2017, sólo nueve países que habían ratificado la CDPD también habían aprobado una nueva constitución después de la ratificación del tratado. Y, sin embargo, en este pequeño grupo, la presencia de protecciones constitucionales cruciales para las personas con discapacidad es -para todos los propósitos prácticos- universal. Los nueve países prohíben específicamente la discriminación por motivos de discapacidad. Los nueve países garantizan el derecho al trabajo de los adultos con discapacidad, o garantizan el derecho al trabajo a todos los ciudadanos y prohíben la
D.

Nuevas
constituciones
tras la adopción
de la CDPD

208 Constitución de la Republica Oriental del Uruguay, 1966 (enmienda del 2005), art. 80.

209 Fiala-Butora et al., 2014, p. 92.

210 Ver Constitute Project, sin fecha.

211 Guyana, 2003. 
discriminación por motivos de discapacidad al mismo tiempo. Los nueve países también garantizan el derecho a la educación de los niños con discapacidad o garantizan el derecho a la educación de todos los niños y prohíben la discriminación por motivos de discapacidad al mismo tiempo. Los nueve garantizan los derechos a la salud de las personas con discapacidad o garantizan los derechos a la salud de todos y prohíben la discriminación por motivos de discapacidad al mismo tiempo. Los nueve garantizan el derecho a la libertad directamente o otorgan este derecho a todos y prohíben la discriminación por motivo de discapacidad, y ocho de los nueve hacen lo mismo por el derecho a la libertad.

Incluso las disposiciones constitucionales que son mucho menos frecuentes, como las relativas a la accesibilidad y los ajustes razonables, tienen más probabilidades de ser adoptadas durante la redacción de una nueva constitución. De los únicos cuatro países del mundo que constitucionalmente mandatan las escuelas accesibles, dos introdujeron su constitución después de ratificar la CDPD. De los únicos siete países del mundo que garantizan o aspiran a la integración de los estudiantes con discapacidad en la educación, dos incluyeron esta disposición en una nueva constitución posterior a la CDPD, al igual que cuatro de los nueve países que garantizan constitucionalmente la accesibilidad en el transporte y/o espacios públicos. Además, las tres constituciones a nivel mundial que garantizan el derecho a ocupar cargos legislativos a las personas con discapacidad fueron redactadas por países después de la ratificación de la CDPD, al igual que dos de las tres constituciones a nivel mundial que garantizan el derecho al voto. Todas estas cifras muestran una creciente consideración de los marcos constitucionales como el lugar apropiado para implementar las obligaciones internacionales creadas por la CDPD y, en general, ampliar los derechos y libertades de las personas con discapacidad.

E. En general, los datos presentados en este capítulo revelan que, en los Conclusión cuatro tipos de derechos y libertades fundamentales examinados, la proporción de constituciones nacionales que garantizan la protección de las personas con discapacidad sigue siendo una clara minoría mundial. Esto es especialmente cierto cuando se compara esta cifra con la proporción de constituciones globales que protegen de la discriminación por motivos de sexo/género, raza/etnia o religión.

Sin embargo, esta cifra general oculta el progreso reciente y acelerado. Si bien el $11 \%$ de todas las constituciones vigentes que se aprobaron antes de 1990 garantizan explícitamente la igualdad o la no discriminación por motivos de discapacidad, el 71\% de las adoptadas en 2010-2017 lo hacen. Se pueden observar tendencias similares en el acceso constitucional a los de- 
rechos sociales y económicos de las personas con discapacidad, incluidos los relacionados con el empleo, la educación y la atención médica. Esta trayectoria refleja el impacto que el movimiento por los derechos de las personas con discapacidad ha tenido en el discurso de los derechos humanos y en la posterior modernización de los marcos legales, y es especialmente notable en aquellos países que promulgaron una nueva constitución después de haber firmado la CDPD.

Sabemos que los avances constitucionales en un país específico pueden tener un efecto dominó fuera de las fronteras de ese país. Las normas legales, las culturas y las formas de razonamiento con frecuencia se polinizan de forma cruzada en todo el mundo. Por ejemplo, una propuesta de enmienda sobre igualdad de la coalición de derechos de las personas con discapacidad Initiativkreis Gleichstellung Behinderter (Iniciativa para la igualdad de las personas con discapacidad), leída públicamente ante la Comisión Constitucional Alemana en 1992, atrajo fuertes influencias de la entonces relativamente reciente Carta Canadiense de Derechos y Libertades que otorga igual protección legal a las personas con discapacidades físicas o mentales. ${ }^{212}$ Dos años después, el art. 3 de la Ley Fundamental de Alemania se modificó para incluir la frase: "Nadie podrá ser perjudicado a causa de un impedimento físico o psíquico".213

La promulgación de una nueva constitución es un hecho poco común en comparación con la frecuencia relativamente mayor de enmiendas constitucionales. Sin embargo, el proceso de enmienda a menudo se ve limitado por barreras políticas y de procedimiento que limitan la entrada en vigor de protecciones fuertes para las personas con discapacidad. En contraste, la redacción de una nueva constitución puede ofrecer oportunidades únicas para el progreso transformador, como la que Chile tiene ahora. Esto es aún más cierto con la participación de los ciudadanos con discapacidad en la redacción. Si bien la CDPD es, evidentemente, un instrumento internacional vinculante, también es el producto final de décadas de trabajo de promoción de las OPD. Esta promoción ha llevado a una codificación cada vez mayor -tanto en la CDPD como en las constituciones que se han promulgado con posterioridad a su entrada en vigor- de cómo se ve un marco justo y equitativo de derechos y libertades para las personas con discapacidad en 2021. Tanto como piedra angular del sistema legal de un país, como una declaración de sus valores colectivos, las nuevas constituciones como la de Chile pueden seguir desempeñando un papel clave en la expansión de los derechos de las personas con discapacidad en todo el mundo.

212 Canadian Charter of Rights and Freedoms, 1982 (enmienda de 1993), art. 15(2); Heyer, 2002, pp. 723-762.

213 Constitución de Alemania, 1949 (con enmiendas hasta 2014). 


\section{- BIBLIOGRAFIA}

Acción directa de inconstitucionalidad (2016)

Superior Tribunal Federal de Brasil. ADI 5357.

Acta Constitucional de Dinamarca (1953).

Amparo Directo En Revisión 1387/2012 (2014) (México).

Disponible en: http://www2.scjn.gob. $m x / j u r i d i c a / e n g r o-$ ses/1/2012/10/2_139091_1794.doc (Consulta: 24 agosto 2021).

Bryde, B. y Stein, M.A. (2012)

'General Provisions Dealing with Equality', en Tushnet, M. et al., Routledge Handbook of Constitutional Law. Abingdon: Routledge, pp. 287-300.

Buck vs. Bell (1927)

Corte Suprema de Estados Unidos.

Canadian Charter of Rights and Freedoms (1982)

Enmiendas hasta 1993.

Constitución de Alemania (1949)

Con enmiendas hasta 2014. Disponible en: https://www.constituteproject. org/constitution/German_Federal_Republic_2014.pdf?lang=es (Consulta: 24 agosto 2021).

Constitucion de España (1978)

Enmiendas hasta 2011. Disponible en: https://www.constituteproject.org/ constitution/Spain_2011.pdf?lang=es (Consulta: 24 agosto 2021).

Constitución de India (1949)

Enmiendas hasta 2016.

Constitución de la República de Malawi (1994)

Enmiendas hasta 2017.

Constitución de la República de Uganda (1995)

Enmiendas hasta 2017.

Constitución de la Republica del Ecuador (2008)

Enmiendas hasta 2015. Disponible en: https://www.constituteproject.org/ constitution/Ecuador_2021.pdf?lang=es (Consulta: 24 agosto 2021). 
Constitución de la República Democrática de Timor-Leste (2002).

Constitución de la Republica Oriental del Uruguay (1966)

Enmiendas hasta 2005. Disponible en: https://www.constituteproject.org/ constitution/Uruguay_2004.pdf?lang=es (Consulta: 24 agosto 2021).

Constitución de los Estados Unidos Mexicanos (1917)

Enmiendas hasta 2017. Disponible en: https://www.constituteproject.org/ constitution/Mexico_2015.pdf?lang=es (Consulta: 24 agosto 2021).

Constitución de Malta (1964)

Enmiendas hasta 2016.

Constitución Política de la Republica Federativa del Brasil (1988)

Enmiendas hasta 2017. Disponible en: https://www.constituteproject.org/ constitution/Brazil_2017.pdf?lang=es (Consulta: 24 agosto 2021).

Constitución Política del Estado Plurinacional de Bolivia (2009)

Disponible en: https://www.constituteproject.org/constitution/Bolivia_2009. pdf?lang=es (Consulta: 24 agosto 2021).

Constitute Project (sin fecha)

Disponible en: https://www.constituteproject.org/?lang=es (Consulta: 24 agosto 2021).

Drew, N. et al. (2011)

'Human Rights Violations of People With Mental and Psychosocial Disabilities: An Unresolved Global Crisis', The Lancet, 378(9803):1664-1675.

Ecuador (2012)

Ley Orgánica de Discapacidades. Registro Oficial, IV(796). Disponible en: https://www.consejodiscapacidades.gob.ec/wp-content/uploads/downloads/2014/02/ley_organica_discapacidades.pdf (Consulta: 24 agosto 2021).

Eldridge vs. British Columbia (Attorney General) (1997)

Corte Suprema de Columbia Británica.

Evans, E., et al. (2012)

'Service Development for Intellectual Disability Mental Health: A Human Rights Approach', Journal of Intellectual Disability Research, 56(11):1098-1109. 
Fiala-Butora, J. (2014)

'The Democratic Life of the Union: Toward Equal Voting Participation for Europeans with Disabilities', College of William \& Mary Law School Faculty Publications, 55(1):71-104.

Filmer, D. (2008)

'Disability, Poverty, and Schooling in Developing Countries: Results from 14 Household Surveys', World Bank Economic Review, 22:141-163.

Guyana (2003) Act No. 10 of 2003. Constitution (Amendment) (NO. 2) Act 2003.

Disponible en: https://parliament.gov.gy/documents/acts/4619-act_no_10_ of_2003.pdf (Consulta: 24 agosto 2021).

Harpur, P. y Stein, M.A. (2019)

'Children with Disabilities, Human Rights, and Sustainable Development', en Fenton-Glynn, C. (ed.) Children's Rights and Sustainable Development. Cambridge: Cambridge University Press, pp. 139-164.

Heyer, K. (2002)

'The ADA on the Road: Disability Rights in Germany', Law \& Social Inquiry, 27(4):723-762.

Heymann, J. y McNeill, K. (2013)

Children's Chances: How Countries Can Move from Surviving to Thriving. Cambridge, MA: Harvard University Press.

Heymann, J., Sprague, A. y Raub, A. (2020)

Advancing Equality. Berkeley, CA: University of California Press.

Jones, M. (2007)

'Does part-time employment provide a way of accommodating a disability?', The Manchester School, 75(6):695-716.

Lawson, A. y Waddington, L. (2018)

The UN Convention on the Rights of Persons with Disabilities in Practice. Oxford: Oxford University Press.

Lazar, J. y Stein, M.A. (2017)

Disability, Human Rights, and Information Technology. Philadelphia: University of Pennsylvania Press.

Lord, J. y Stein, M.A. (2013)

'Prospects and Practices for CDPD Implementation in Africa', African Disability Rights Yearbook, 1:109-110. 
Lord, J., Stein, M.A. y Fiala-Butora, J. (2014)

'Facilitating an Equal Right to Vote for Persons with Disabilities', Journal of Human Rights Practice, 6(1):115-139.

\section{Maldonado, S. (2006)}

Trabajo y Discapacidad en el Perú: Mercado Laboral, Políticas Publicas e Inclusión Social. Lima, Perú: Fondo Editorial del Congreso del Perú y Programa de Naciones Unidas para el Desarrollo.

Mannan, H. et al. (2012)

'Core Concepts of Human Rights and Inclusion of Vulnerable Groups in the Disability and Rehabilitation Policies of Malawi, Namibia, Sudan, and South Africa', Journal of Disability Policy Studies, 23(2):67-81.

Mitra, S. y Sambamoorthi, U. (2009)

'Wage differential by disability status in an agrarian labor market in India', Applied Economic Letters, 16(14):1393-1398.

National Association of the Deaf vs. Union of India (2011)

Tribunal Superior de Delhi. W.P.(C) 10849/2009.

$\operatorname{OECD}(2010)$

Sickness, Disability and Work: Breaking the Barriers. A Synthesis of Findings Across OECD Countries. Paris: OECD Publishing.

Organización de Naciones Unidas (2006)

Convención sobre los derechos de las personas con discapacidad.

Ranjit Kumar Rajak vs. State Bank of India (2009)

Tribunal Superior de Bombay. 5 Bom CR 227.

Redley, M. et al. (2012)

'The Voting Rights of Adults with Intellectual Disabilities: Reflections on the Arguments, and Situation in Kenya and England and Wales', Journal of Intellectual Disability Research, 56(11):1026-1035.

Schur, L. (2002)

'Dead end jobs or a path to economic well being? The consequences of non-standard work for people with disabilities', Behavioral Sciences and the Law, 20:601-620.

Stein, M.A. et al. (2009)

'Health Care and the UN Disability Rights Convention', The Lancet, 374(9704):1796-1798. 
UNESCO (2014)

Education for All Monitoring Report 2013/2014. Paris: UNESCO Publishing.

UNICEF (sin fecha)

Children and Young People with Disabilities Fact Sheet. Disponible en: www. unicef.org/disabilities/files/Factsheet_A5__Web_REVISED.pdf (Consulta: 24 agosto 2021).

United Nations Enable (sin fecha)

Fact Sheet on Persons with Disabilities. Disponible en: https://www.un.org/ development/desa/disabilities/resources/factsheet-on-persons-with-disabilities.html (Consulta: 24 agosto 2021).

Van Weele, E. (2012)

'The UN Convention on the Rights of Persons with Disabilities in the Context of Human Rights Law', en Anderson, J. y Philips, J. (eds.) Disability and Universal Human Rights: Legal, Ethical, and Conceptual Implications of the Convention on the Rights of Persons with Disabilities. Utrecht: Netherlands Institute of Human Rights, pp. 9- 30.

Wilson-Kovacs, D. et al. (2008)

'Just because you can get a wheelchair in the building doesn't necessarily mean that you can still participate: Barriers to the career advancement of disabled professionals', Disability \& Society, 23(17):705-717.

World Health Organization (2011)

World Report on Disability. Malta: Organización Mundial de la Salud.

World Health Organization (2020)

Disability and Health. Disponible en: https://www.who.int/en/news-room/ fact-sheets/detail/disability-and-health (Consulta: 24 agosto 2021). 
